\title{
How much water can be transported by the subducted serpentinized mantle into the deep Earth?
}

\author{
JULIA RIBEIRO ${ }^{1}$, YANG LIAO ${ }^{2}$, JIAN LIN ${ }^{3}$, XINLEI SUN ${ }^{4}$ \\ AND JEFF RYAN ${ }^{5}$ \\ ${ }^{1}$ Guangzhou Institute of geochemistry \\ ${ }^{2}$ WHOI \\ ${ }^{3}$ South China Sea Institute of Oceanology, Chinese Academy of \\ Sciences \\ ${ }^{4}$ GIG-CAS \\ ${ }^{5}$ University of South Florida \\ Presenting Author: juliaribeiro_mail@yahoo.fr
}

The exchanges in water between the Earth's surface and its deeper interior have contributed to plate motions and habitability of our planet over geological times. Subduction zones efficiently recycle surface water back into the deep Earth, but the extent to which the subducted plate is hydrated remains largely unknown. The serpentinized mantle, which formed at mid-ocean ridges and further subducts to trenches, is believed to be one of the major water carriers at subduction zones. Yet, its degree of hydration remains debated. Hydration and subsequent serpentinization of the lithospheric mantle results in a buoyant layer, which may limit its ability to subduct. To further quantify the flux of water that can be transported by the serpentinized mantle, here we present a study based on half-space cooling model and isostasy in the Cascadia and the Izu-Bonin-Mariana (IBM) subduction zones. Assuming isostatic equilibrium for the Pacific plate, our 2D modeling suggests that the thickness of a fully serpentinized layer in the upper mantle could have an upper limit of 6-km for Cascadia and $20-\mathrm{km}$ for IBM to permit subduction. However, a serpentinized mantle layer of $\sim 1 \mathrm{~km}$ thick for Cascadia and $\sim 3$ $\mathrm{km}$ thick for IBM best fit the depth of the Pacific Ocean. The lithospheric mantle could thus carry four times more serpentinebound water down to the IBM trench $\left(4.91 \times 10^{+10} \mathrm{~g} / \mathrm{km} / \mathrm{yr}\right)$, compared to the Cascadia trench $\left(1.21 \times 10^{+10} \mathrm{~g} / \mathrm{km} / \mathrm{yr}\right)$. If our predictions are correct, (i) the subducting mantle might not be the major water carrier at subduction zones, and (ii) the water fluxes emitted in the IBM and Cascadia subduction zones might exceed the fluxes of water transported down to the trenches. Additional water reservoirs could thus be required to contribute to the exceeding water fluxes at subduction zones and to maintain sealevels for millions of years. 